IZA DP No. 10386

Biology and Gender in the Labor Market

Deborah A. Cobb-Clark

November 2016 


\title{
Biology and Gender in the Labor Market
}

\author{
Deborah A. Cobb-Clark \\ University of Sydney, IZA \\ and ARC Life Course Centre
}

\section{Discussion Paper No. 10386 November 2016}

\author{
IZA \\ P.O. Box 7240 \\ 53072 Bonn \\ Germany \\ Phone: +49-228-3894-0 \\ Fax: +49-228-3894-180 \\ E-mail: iza@iza.org
}

\begin{abstract}
Any opinions expressed here are those of the author(s) and not those of IZA. Research published in this series may include views on policy, but the institute itself takes no institutional policy positions. The IZA research network is committed to the IZA Guiding Principles of Research Integrity.

The Institute for the Study of Labor (IZA) in Bonn is a local and virtual international research center and a place of communication between science, politics and business. IZA is an independent nonprofit organization supported by Deutsche Post Foundation. The center is associated with the University of Bonn and offers a stimulating research environment through its international network, workshops and conferences, data service, project support, research visits and doctoral program. IZA engages in (i) original and internationally competitive research in all fields of labor economics, (ii) development of policy concepts, and (iii) dissemination of research results and concepts to the interested public.
\end{abstract}

IZA Discussion Papers often represent preliminary work and are circulated to encourage discussion. Citation of such a paper should account for its provisional character. A revised version may be available directly from the author. 
IZA Discussion Paper No. 10386

November 2016

\section{ABSTRACT}

\section{Biology and Gender in the Labor Market ${ }^{1}$}

Can biology help us to better understand gender differences in labor market behavior and outcomes? This chapter reviews the emerging literature which sheds light on this question, considering research in four broad areas: i) behavioral endocrinology; ii) human genetics; iii) neuroeconomics; and iv) sensory functioning and time-space perceptions.

JEL Classification: J31, A12, Z0

Keywords: gender wage gap, labor market outcomes, human biology, neuroeconomics, behavioral genetics

Corresponding author:

Deborah A. Cobb-Clark

School of Economics

University of Sydney

Merewether Building, cnr City Road/Butlin Avenue

NSW 2006 Sydney

Australia

E-mail: deborah.cobb-clark@sydney.edu.au

\footnotetext{
1 Prepared for inclusion in the Oxford Handbook on the Economics of Women, ed. Susan L. Averett, Laura M. Argys and Saul D. Hoffman (New York: Oxford University Press. Forthcoming, 2018). I would like to thank Anne Gielen, Marian Vidal-Fernandez and Agnieszka Tymula for their thoughtful comments and Melisa Bubonya for her exceptional research assistance.
} 


\section{Introduction}

The notion that there is a biological basis for human behavior, including economic behavior, is certainly not new. Nearly a century ago, Marshall $(1920,772)$ argued that economics "is a branch of biology broadly interpreted”. Decades later, as biologists began to consider social behavior through the lens of evolution, the field of "socio-biology", emerged. Economists were quick to note that the analytical concepts adopted by socio-biologists - competition, the allocation of limited resources (e.g. food and energy), and efficient adaptation to the environment - were strikingly familiar (see Becker 1976, Hirshleifer 1977). Not surprisingly, conceptual arguments for the biological basis of fundamental economic parameters such as social, risk, and time preferences began to be debated (see Rogers 1994, Robson 1996, 2001). Despite this, the biological origins of human behavior remained largely outside the purview of neoclassical economic modelling.

Recently, there has been a resurgence of interest in the capacity for a vast array of biological concepts to enhance our understanding of economic decision making. While there are potentially many explanations for this, three seem particularly compelling. First, more intense scrutiny of the biological basis for economic behavior is a natural extension of the development of behavioral economics and neuroeconomics as fields of study. Some of the cognitive biases and non-standard preferences inherent in behavioral economics may have biological roots, ${ }^{2}$ while neuroeconomics has highlighted the biological constraints on decision making imposed by the human brain. Second, there is enormous - largely as yet unrealized - potential to deepen our understanding of economic decision making by incorporating biological concepts into our theoretical frameworks. Robson $(2001,11)$, in particular, argues that "it seems that the marginal product of work on biological foundations now exceeds that of work on more elaborate higher level models of economic behavior". Finally, scientific developments in mapping the brain and the human genome have opened the door to empirically testing hypotheses which even a decade ago might have remained merely interesting conjectures. Beauchamp et al. (2011, 58), for example, make the important observation that "the costs of comprehensively genotyping human subjects have fallen to the point where major funding bodies, even in the social sciences, are beginning to incorporate genetic and biological markers into major social surveys”. The availability of such data will

\footnotetext{
${ }^{2}$ See Robson (2001), for example, who discusses the evidence for a biological basis to hyperbolic discounting and the concern for status.
} 
no doubt give birth to new empirical research exploring the biological underpinnings of social and economic behavior.

It is interesting to contemplate what these developments might mean for labor economists interested in the role of gender in the labor market. Over the past 50 years, there has been a dramatic decline in the gender disparity in key labor market outcomes including wages, participation rates and occupational distributions (e.g. Blau and Kahn forthcoming, Blau and Kahn 2006, Blau, Brummund, and Liu 2013, O’Reilly et al. 2015). ${ }^{3}$ Despite this, the gender gap in pay has not completely closed and, in some countries, has even widened (see Weichselbaumer and Winter-Ebmer 2005, O’Reilly et al. 2015). This arrested progress has left researchers investigating non-traditional explanations for the role of gender in the labor market (Bertrand 2011). Biological sources of gender differences are an obvious line of inquiry given the pervasiveness of gender wage gaps around the world.

Can biology help us to better understand gender differences in labor market behavior and outcomes? This chapter reviews the emerging literature which sheds light on this question, considering research in four broad areas: i) behavioral endocrinology; ii) human genetics; iii) neuroeconomics; and iv) sensory functioning and time-space perceptions. ${ }^{4}$ Despite the long-standing conceptual links between economics and biology, empirical research in these areas is still very much in its infancy. Often the research focus is on biologically-based differences in men's and women's abilities or decision making more generally and we will be left to speculate about the implications for labor market outcomes specifically. In light of this, the chapter concludes by highlighting some of the fundamental issues that we do not yet understand and offering some priorities for future research.

Developing a deeper understanding of the importance of biological factors in generating the gender inequality that we observe in labor-market outcomes is important for a number of reasons. If biology even partially drives the human capabilities that workers bring to the labor market and the outcomes that they achieve, we risk the standard omitted variable bias problem if our models ignore biology completely. Estimates of the roles of psychological, cultural, social or economic factors in producing gender disparities become exceedingly difficult to interpret and are not subject to a causal interpretation. Moreover, although the stark nature-nurture dichotomy is not a helpful representation of reality (see

\footnotetext{
${ }^{3}$ See Bertrand, Kamenica, and Pan (2015) who discuss the range of factors that have been identified as contributing to these gains.

${ }^{4}$ Bertrand (2011) provides an excellent overview of new perspectives on the role of gender in labor market outcomes. In addition, the following are important reviews of gender differences in i) risk aversion (Eckel and Grossman 2008a, Azmat and Petrongolo 2014); ii) competitive behavior (Booth 2009, Niederle and Vesterlund 2011); iii) preferences (Croson and Gneezy 2009); and iv) gender identity(Akerlof and Kranton 2000).
} 
Halpern 2012 on this point), sorting out the relative importance of biological versus environmental influences on gender disparities may nonetheless have important policy implications (see Bertrand 2011). Finally richer models incorporating more realistic biological foundations might not only generate testable empirical predications, but also help us to identify potentially productive interventions (Dreber and Hoffman 2010).

Before beginning, it is useful to make a few observations about language. Sometimes researchers distinguish between "gender differences" which are psychologically, socially or culturally driven and "sex differences" which are biologically driven (see Hines 2004, Halpern 2012). “The fact that biological sex creates very different environments for males and females from the moment of birth means that differences in biological sex are always associated with different environmental experiences” (Halpern 2012, 51). Given this, and the fact that our focus is on labor market outcomes, not biological functions per se, I have chosen to uniformly use the term "gender" throughout because I regard it as the more expansive term.

\section{Behavioral Endocrinology}

Potentially, robust findings on the endocrinology of economic behavior could profoundly influence our understanding of the biological basis of economic outcomes including the gender wage gap.

(Pearson and Schipper 2013, 2)

Behavioral endocrinology is the study of the interactions between hormonal processes and behavior. ${ }^{5}$ The emerging literature in this area is of particular interest to those interested in gender differences in labor market outcomes. After all, one of the major biological differences between men and women is in their relative concentrations of reproductive hormones; estrogen, progesterone, and testosterone. Both men and women have measurable quantities of all three, however, hormone concentration levels vary by sex, life experiences (e.g. pregnancy, exposure to competitive situations, etc.) and across the lifecycle. Researchers are increasingly using this variation to link reproductive hormones to fundamental economic preferences (e.g. risk and social preferences, attitudes towards competition, etc.) and to labor market behavior.

\footnotetext{
${ }^{5}$ See Nelson (2011) for an overview of the history of behavioral endocrinology.
} 


\subsection{Hormones and Fundamental Economic Preferences}

Hormonal processes may affect economic behavior - and hence labor market outcomes through the role they have in influencing risk, time, or social preferences and attitudes towards competition. There is a large literature documenting the disparity in men's and women's attitudes towards risk and competition. Recent reviews conclude that the findings of this research are in general consistent with women being more risk averse (Eckel and Grossman 2008b, Croson and Gneezy 2009) and more likely to avoid competitive environments (Croson and Gneezy 2009, Niederle and Vesterlund 2011). Many researchers are raising questions about the extent to which hormones, in particular testosterone, might provide an explanation for these gender disparities.

Exposure to testosterone at critical developmental stages, particularly during fetal development and puberty, is thought to have the potential to permanently alter behavior (Apicella, Carré, and Dreber 2015). Researchers studying the effects of testosterone on behavior typically rely one of two approaches to measuring it. Testosterone levels fluctuate across time - even across the hours of the day - and can be measured with a saliva test, while a low second to fourth digit finger ratio (2D:4D) is commonly used as a marker of prenatal exposure to testosterone (Manning et al. 1998). Prenatal exposure to testosterone (using 2D:4D) has been linked to increased aggression (Hampson, Ellis, and Tenk 2008), while testosterone levels in adolescent boys and adult men have been positively associated with increased aggression and competitiveness (Archer 2006, Carré and McCormick 2008) and risk-taking (Coates and Herbert 2008).

Importantly, women's responses to competitive situations have also been linked to their testosterone levels (Bateup et al. 2002), as well as to their menstrual cycles and contraceptive pill usage (Chen, Katuščák, and Ozdenoren 2013, Pearson and Schipper 2013, Wozniak, Harbaugh, and Mayr 2014). Bateup et al. (2002) find, for example, that in the leadup to a competitive match, female rugby players experience an anticipatory rise in testosterone that is positively associated with increased self-reported focus and team bonding. Chen, Katuščák, and Ozdenoren (2013) study sealed-bid auctions in a laboratory setting. They find that the menstrual cycle influences the bidding behavior of women who use the contraceptive pill, but has virtually no effect on the bidding behavior of women who do not. Finally, women appear to selectively reduce risky activities that expose them to sexual assault during ovulation (Bröder and Hohmann 2003). These studies suggest that reproductive hormones are associated with the risk-taking and competitive behavior of women as well as men. 
Yet the capacity for sex hormones themselves to drive observed gender disparities in the fundamental economic parameters remains unclear. Despite large fluctuations in hormone levels, women are as likely as men to adhere to the Generalized Axiom of Revealed Preferences - the standard test of economic rationality - at all phases of their menstrual cycle (Lazzaro et al. 2016). Moreover, the evidence for a link between hormones and standard time and risk preferences is at best mixed, with some studies generating results consistent with such a link (Dreber and Hoffman 2007, Takahashi et al. 2008, Brañas-Garza and Rustichini 2011, Garbarino, Slonim, and Sydnor 2011) and others not (Apicella et al. 2008, Sapienza, Zingales, and Maestripieri 2009, Schipper 2012, Drichoutis and Nayga 2015). ${ }^{6}$ Most of this evidence is correlational. However, in an important study of post-menopausal women, Zethraeus et al. (2009) find no effect of randomly administered testosterone or estrogen on the results of numerous economic experiments designed to measure altruism, reciprocal fairness, trust, trustworthiness, and risk attitudes. ${ }^{7}$ They conclude that "our study offers no support for the hypothesis that sex hormones affect economic behavior” (Zethraeus et al. 2009, 6536). In contrast, after reviewing placebo-controlled single hormone administration studies that investigate the hormonal regulation of human social behavior, Bos et al. (2012, 31) argue that an increasing number of studies show that hormones are "causally implicated in human behavior".

\subsection{Hormones and Labor Market Outcomes}

A rapidly increasing number of studies investigate the relationship between sex hormones and labor market outcomes directly. Only rarely do researchers rely on experimental variation in hormone levels to identify their effects, however. ${ }^{8}$ Instead, exposure to prenatal testosterone is identified through information about twin births or 2D:4D finger ratios, while saliva tests or information about women's menstrual cycles are often used to capture variation in circulating hormone concentrations.

It is well-documented that women have higher rates of work absenteeism than men (see VandenHeuvel and Wooden 1995, Patton and Johns 2007), raising questions about the potential for hormone levels to explain gender patters in work attendance. Using personnel data from an Italian bank, for example, Ichino and Moretti (2009) show that the absences of

\footnotetext{
${ }^{6}$ See Drichoutis and Nayga (2015) for a review.

${ }^{7}$ Results based on the random administration of hormones are more convincing than those from studies that proxy hormone level using the number of days since a woman's last period since women ovulate at different stages of their cycle and many do not have the 28-day cycle that is typically assumed.

${ }^{8}$ There are some exceptions. See Bos et al. (2012) and Zethraeus et al. (2009).
} 
women aged less than 45 follow a 28-day cycle (the length of a typical menstrual cycle), while those of men and women over the age of 45 do not. This leads the authors' to conclude that women's menstrual cycle increases their absenteeism. Moreover, absenteeism is associated with a lower earnings penalty for women, which the authors argue is consistent with absenteeism being a noisier signal of productivity for women. Overall, the authors conclude that - despite this lower penalty - at least 14 percent of the gender earnings differential is attributable to the increased absenteeism associated with women's 28-day menstrual cycle.

In a subsequent paper, however, Herrmann and Rockoff (2012) reanalyze Ichino and Moretti's data and show that their results are not robust to coding choices or specification changes. More importantly, Herrmann and Rockoff argue that 5-day work weeks can generate large differences in group-level absence rates at multiples of 7 days making it difficult to identify the effect of 28-day menstrual cycles from the pattern of absences alone. ${ }^{9}$ Consequently, Herrmann and Rockoff (2013) turn to data from the National Health Interview Survey to investigate the relationship between work absences, earnings, and self-reported menstrual health problems. They find that completely eliminating menstrual problems would reduce the gender gap in illness-related absences from 0.96 days to approximately $0.65-0.46$ and improve the gender earnings gap by a very modest 1 percent.

A few studies have linked prenatal testosterone exposure (as measured with the 2D:4D finger ratio) and circulating testosterone to occupational choice. A low 2D:4D (indicating higher levels of prenatal testosterone) has been associated with a preference for masculine occupations among both male and female students in Germany (Weis, Firker, and Hennig 2007), but, contrary to expectations, with a preference for feminine occupations among female students in the United States (Lippa 2006). Similarly, Nye and Orel (2015) investigate the occupational preferences of a large sample $(n=8646)$ of working-age Russians reporting self-measurements of their 2D:4D finger ratio. They find a number of significant differences in the mean 2D:4D finger ratio of workers in different occupations. Overall, they conclude that the pattern is generally consistent with a low (high) 2D:4D finger ratio being associated with more stereotypical masculine (feminine) interests. Analyzing the occupational choices of more than a quarter of a million respondents in an internet survey, Manning et al. (2010) also find that workers in male-typical occupations have lower 2D:4D

\footnotetext{
${ }^{9}$ Specifically, Hermann and Rockoff argue that the spikes in absences at seven-day intervals may be mechanical artifacts of the five-day work week. Italian banks are generally not open on weekends. Thus, conditional on the date of a prior absence, the probability that a bank is open - and therefore that another absence could occur seven days later (or any multiple of seven days later) is considerably higher than for any other period.
} 
finger ratios. Finally, Sapienza, Zingales, and Maestripieri (2009) find that MBA students from the University of Chicago who are high in testosterone and low in risk aversion are more likely to choose risky careers in finance.

This self-selection of MBA students with relatively high testosterone levels into the financial sector may be quite sensible given the positive association between testosterone and successful real-world financial decision making. Coates and Herbert (2008) study the outcomes of men engaged in "high-frequency" trading in London. They find that circulatory testosterone levels measured before trading begins using a saliva test are positively associated with daily profits. At the same time, there is a feedback effect between market conditions and trading results on hormone levels, with men's cortisol levels (a marker of stress) rising with both the variance of trading results and market volatility. These short-run results captured over an 8-day period appear to persist over the longer run. Specifically, Coates, Gurnell, and Rustichini (2009) demonstrate that a lower 2D:4D finger ratio (a marker of prenatal exposure to testosterone) is positively associated with higher long-term profitability and an increased chance of surviving as a trader irrespective of market conditions.

In related research, Guiso and Rustichini (2011) demonstrate that there may also be a hormonal basis to entrepreneurial skill. Specifically, they find that Italian CEOs with higher exposure to prenatal testosterone (a lower 2D:4D ratio) manage larger firms (in terms of numbers of employees, sales, and value). Moreover, their firms grow 0.5 percentage points faster on average over the years the CEO was in control. In contrast, Van der Loos, Haring, et al. (2013) do not find any significant relationship between testosterone and entrepreneurial behavior in two independent, large population-based samples of men.

While the literature in behavioral endocrinology has to-date been heavily reliant on the 2D:4D ratio as a marker of prenatal exposure to testosterone, some researchers are beginning to use opposite-sex twinning as a source of plausibly exogenous variation in prenatal testosterone exposure. There is substantial evidence that among animals, testosterone transfers from male fetuses to their littermates (see Hines 2004), leading to the possibility that testosterone transfers between human twins as well. If true, this implies that females from opposite-sex twin pairs have greater exposure to testosterone in the womb than do females from same-sex twin pairs. Similarly, male same-sex twin pairs presumably also have greater prenatal testosterone exposure than do male opposite-sex twins (see Cronqvist et al. 2015, Gielen, Holmes, and Myers 2016 for reviews). Research exploiting this source of variation in prenatal testosterone provides an important opportunity to assess the robustness of findings across alternative measures. Moreover, the comparison of same- and opposite-sex twins 
naturally lends itself to an assessment of the consequences of prenatal testosterone on gender disparities in outcomes.

Using a large sample of dizygotic twin pairs from the Swedish twins registry, Cronqvist et al. (2015) find that prenatal environments partially explain heterogeneity in financial behavior in adulthood. Women with a male co-twin trade more frequently, invest in more risky financial assets, and have portfolios with more individual stocks (relative to mutual funds) and more volatility than do those with a female co-twin. Singleton women raised with a male sibling do not exhibit the same disparity in financial behavior suggesting that the result is driven by prenatal conditions rather than any difference in socialization or home environment associated with having a brother rather than a sister. Overall, the gender gap in financial risk-taking is estimated to be as much as 39 percent smaller for women with a male co-twin.

Interestingly, any prenatal testosterone from having a male co-twin does not appear to convey the same advantage in the labor market that it does in the financial market. Gielen, Holmes, and Myers (2016) construct a sample of dizygotic twins and closely-spaced singletons from Dutch administrative data. Women with a twin brother earn approximately 1.2 percent less than women with a twin sister, while women who are singletons earn 0.4 percent less if they have a brother rather than a sister. The resulting difference-in-difference estimate (-0.8 percent) implies that prenatal exposure to testosterone does not advantage women in the labor market and may even lead to a slight decrease in wages. In contrast, same-sex twinning results in a 1.7 percent increase in the wages of men.

\section{Human Genetics}

There is no escape from the conclusion that nature prevails enormously over nurture when the differences of nurture do not exceed what is commonly to be found among persons of the same rank of society and in the same country.

(Galton 1883, 241)

Two distinct branches of research exploring the links between human genetics and individual social and economic outcomes are of particular interest to economists. The first is a wellestablished research field - behavioral genetics - that analyzes the degree to which heterogeneity in human behavior is explained by genetic endowments rather than environmental factors. The second is an emerging research area - increasingly referred to as 
genoeconomics - that attempts to link economic outcomes to the presence of specific genes. In what follows, I discuss the potential for research findings in both branches of genetics research to shed light on the drivers of gendered labor market outcomes.

\subsection{Behavioral Genetics}

The foundation of behavioral genetics is often attributed to Sir Francis Galton who was the first to study the transmission of talent from parents to their offspring. ${ }^{10}$ Behavioral geneticists exploit family relationships, twin births, and adoption as a means of decomposing the heterogeneity in individual outcomes into two components; one due to environmental factors and the other due to genetic factors. In its simplest form, the behavioral genetic model relies on very strong assumptions about functional form and, importantly, the independence of genetic and family effects (see Beauchamp et al. 2011). There is an increasing recognition, however, that heredity and environments have an intertwined influence on human development, implying that behavioral genetic designs often only estimate genetic and environmental variation in outcomes within ranges and not in an absolute sense (Ilies, Arvey, and Bouchard 2006).

Nonetheless, over the past several decades, researchers have documented the potential role of genetics - or heritability - in explaining cross-sectional variation in a vast range of traits, attitudes, and behaviors that are relevant to the workplace. Specifically, IQ; social and risk preferences; personality; education; income; financial decision making; job satisfaction and leadership ability have all been argued to be partially heritable (see Ilies, Arvey, and Bouchard 2006, Cesarini et al. 2009). Although estimates themselves are often quite sensitive to the modelling assumptions, it is common for twin studies, for example, to attribute a large share of the heterogeneity in outcomes to genetic factors. In his seminal study, Taubman (1976) concluded that between 18 and 41 percent of the earnings variation for male twins is due to genetic factors, while even in their lower bound estimates Björklund, Jäntti, and Solon (2005) find that genetic factors account for 20 percent of earnings variation for men and more than 10 percent of earnings variation for women. Similarly, approximately 40 percent of the variation in twins' educational outcomes appears to be due to genetic endowments (see Branigan, McCallum, and Freese 2013).

For heritability to play a role in generating gender disparities in the labor market, it would have to be the case that heredity operates differently for men and women, and

\footnotetext{
${ }^{10}$ See Ilies, Arvey, and Bouchard (2006) for a discussion of the historical development of behavioral genetics and its relationship to organizational behavior.
} 
moreover, that heredity acts to disadvantage women on average. ${ }^{11}$ Thus far, there is little empirical evidence that either is the case. Conceptually, however, it is not difficult to imagine gender differences in genetic influences emerging as a type of gene-environment interaction. Zhang et al. (2009), for example, investigate gender differences in the heritability of entrepreneurship. They argue that in less supportive environments - such as the ones women typically face - genetic factors will have a larger influence in determining individual success. In short, genetic influences are expected to play a stronger role in women's entrepreneurial behavior because women experience more discrimination in becoming entrepreneurs. Men's success in becoming entrepreneurs is more closely related to environmental factors and less reliant on genetics because the environment is more supportive for men. Using a sample of twin-pairs, the authors find that women have strong genetic and zero shared-environmental influences on their propensity to become entrepreneurs, while men have zero genetic and large shared-environmental influences. In contrast, Van der Loos, Rietveld, et al. (2013) find evidence of significant heritability in men’s entrepreneurship. Similarly, Le et al. (2011) find that, while men's and women's attitudes to risk differ, there is no gender gap in the heritability of risk attitudes.

If heritability is ultimately shown to contribute to the gender gap in earnings, occupational attainment, entrepreneurship, etc., there are legitimate questions about what this would then imply for labor market policies to ameliorate gender inequality. Goldberger (1979, 346), in particular, cautions against using heritability estimates to undermine active socioeconomic policy through the simplistic argument that "current inequalities are the inevitable dictates of nature”. Manski $(2011,83)$ goes even further by arguing that conceptual and technical issues make research on heritability "fundamentally uninformative for policy analysis". The primary issue is that genetic effects operate at least in part via environmental influences. Parents, for example, are likely to modify the environment in response to their children's genetic endowments. This implies that estimates from behavioral genetics models are difficult to interpret because they are essentially reduced-form estimates from a more general model in which environmental influences are endogenous with respect to genotype (see Beauchamp et al. 2011, Benjamin et al. 2012 for a discussion). Using such estimates for policy development requires a great deal of caution.

\footnotetext{
${ }^{11}$ See Halpern $(2012,168)$ who makes this point with respect to gender differences in cognitive abilities.
} 


\subsection{Genoeconomics}

While behavioral genetics uses population data to draw indirect inferences about the role of genetic endowments overall, molecular genetics is the study of heredity and genetic variation at the molecular level. Benjamin et al. (2008) coined the phrase "genoeconomics" to refer to the use of molecular genetic information in economics. Two primary research strategies are being used to identify the link between genes and behavior: i) candidate gene studies in which an "educated guess" is used to select particular genes for analysis because of their known biological functions; and ii) genome-wide association studies (GWAS) in which researchers look for associations between the outcome of interest and millions of possible genetic variations across the human genome (see Benjamin et al. 2012).

Genetic markers have been identified for a range of preferences, abilities, and outcomes that are potentially useful in understanding heterogeneity in labor market outcomes. These include, for example, risk, time and social preferences; empathy; educational attainment; financial choices; and self-employment (see Ebstein et al. 2010, Beauchamp et al. 2011 for reviews; also Dreber et al. 2009, Zhong et al. 2009, Zhong et al. 2010, Carpenter, Garcia, and Lum 2011). Much of the literature analyzes the genetic basis of economic preference parameters and outcomes measured in a laboratory setting. However, newlyavailable genetic information in major population surveys is opening the door to studying the genetic foundations of economic behavior in real world settings.

In particular, Papageorge and Thom (2016) study the relationship between genes, education, and labor market outcomes utilizing data from the Health and Retirement Study (HRS) which collected genetic samples from more than 15,000 respondents between 2006 2010. The authors construct a 'polygenetic score' which essentially is a weighted average of several different gene-education associations previously identified in the GWAS literature. Genetic scores explain 3.2 - 6.6 percent of the educational variation among HRS respondents depending on model specification. Genetic scores are also associated with labor force participation, early retirement, the wages of college graduates, and wealth.

Similarly, Van der Loos, Rietveld, et al. (2013) investigate the molecular genetic architecture of self-employment using both a classical twin design and analyses of genomewide molecular genetic data. They find that the heritability estimate for self-employment using common single nucleotide polymorphisms (SNPs) is approximately half what is obtained using the classical twin design. While their results lead the authors to conclude that the effects of any single SNP on self-employment are likely to be very small, when 
considered jointly, common SNPs account for a substantial share of the variance in the propensity to be self-employed.

Thus far genoeconomics has produced few, if any, insights for those interested in the biological basis of gender inequality in the labor market. While research findings are intriguing, it is fair to say that genoeconomics has not as yet realized its full potential. Results have been remarkably difficult to replicate, leading some to suggest that many findings are spurious (Beauchamp et al. 2011). Most studies are seriously underpowered because sample sizes are too small, and although much of the promise of geneconomics lies in uncovering the causal mechanisms behind biological processes, the evidence thus far is strictly correlational (Beauchamp et al. 2011, Benjamin et al. 2012, Chabris et al. 2015). Moreover, research has not yet explicitly investigated whether heredity and genetic variation operates differently for men and women - and whether this is an important source of gender disparities. Given the extraordinary richness of the emerging data, addressing this void in the literature would seem to be only a matter of time.

\section{Neuroeconomics}

Existence of sex differences in behavior implies the existence of sex differences in the brain because the brain provides the basis for all behavior.

(Hines 2004, 65)

Neuroeconomics is a new, interdisciplinary research field which draws on the insights and methods of psychology, neuroscience, and economics to understand how economic-decision making actually happens within the brain. The objective is to shed light on the impact the brain's neural systems and computational processes have on the choices that individuals make. Thus far, research has not directly investigated whether there is a neurological basis to gender disparities in economic outcomes. However, ongoing efforts to understand differences in men's and women's i) brain functioning; ii) emotional responses to risk; and iii) selfcontrol all raise the potential for such a link to be discovered in the future.

\subsection{Brain Functioning}

Scientists have shown that while men's and women's brains are largely similar, there are some ways in which they differ. Men's brains tend to be larger in size and slightly different in structure (see Hines 2004). Whether or not these physical differences in men's and women's brains have consequences for their behavior is a matter of intense debate. Baron-Cohen 
$(2003,1)$ argues that "the female brain is predominately hard-wired for empathy. The male brain is predominately hard-wired for understanding and building systems." Seen in this light, Baron-Cohen (2002) believes that autism can be considered as an extreme of the normal male brain profile.

Interestingly, recent research suggests that this categorization of brain types may be useful in understanding gender disparities in labor market outcomes. Drydakis (2015) administered the empathizing and systemizing questionnaires developed by Baron-Cohen et al. (2003) to working-age adults in the U.K. He finds that 'systemizing' traits are associated with higher wages than are 'empathizing' traits, though the wage returns to each vary by occupation, and that 'brain type' helps explain the gender wage gap.

However, the idea that brain functioning might explain observed gender gaps in labor market outcomes is extremely controversial and not yet widely accepted. In particular, Halpern (2012) offers a detailed critique of the underlying science behind the notion that male and female brains are 'essentially different' in the ways that Baron-Cohen describes. She concludes that "the idea that female and make brains are essentially different and that these differences explain why there are more males in the physical sciences and more females in helping professions does not hold up to additional scrutiny” (Halpern 2012, 243). Hines (2004, 222) reaches the same conclusion.

\subsection{Emotions}

There is no doubt that human emotions play a fundamental role in decision making, particularly in situations of risk and uncertainty. Emotions compel us to take certain actions and avoid others. Neuroscientists have made an important contribution in demonstrating that there is a neural basis for human emotions. Different structures within the brain process, transmit, moderate, and help us recall emotions (e.g. LeDoux 1995, Panksepp 1998). ${ }^{12}$ While psychologists tend to be concerned with those emotions that are experienced at the time a decision is made (i.e. anticipatory or immediate emotions), economists have historically been much more likely to focus on anticipated future emotions, such as disappointment and regret (Loewenstein 2000). ${ }^{13}$ It is clear, however, that people react not only cognitively, but also emotionally and physiologically to the presence of risk. Consequently, Loewenstein et al. (2001) argue that accounting for the anticipatory emotions (e.g. fear) associated with risk and

${ }^{12}$ Panksepp (1998) labels the neurological study of humans' basic emotional operating systems 'affective neuroscience'.

${ }^{13}$ See Tymula and Glimcher (forthcoming) for a review of the history of emotions in economics and psychology. 
the conflicts that often occur with cognitive evaluations of the true situation has the potential to explain a wide range of phenomenon that are difficult to understand solely in cognitiveconsequential terms.

Emotions suggest another potential mechanism, i.e. neural systems, linking human biology to gendered labor market behavior. Specifically, men and women appear to differ in the way they evaluate and emotionally respond to risky situations. Experimental evidence, for example, indicates that women depart more strongly from linear probability weighting, implying that they are more risk averse in part because they are less sensitive to changes in probability and are more likely to underestimate large probabilities of gains (Fehr-Duda, De Gennaro, and Schubert 2006, Bruhin, Fehr-Duda, and Epper 2010). There is also evidence that women both overestimate the probability of negative outcomes occurring (Silverman and Kumka 1987, Spigner, Hawkins, and Loren 1993, Flynn, Slovic, and Mertz 1994, Lundborg and Andersson 2008) and experience negative emotions more intensely (Fujita, Diener, and Sandvik 1991, Brody 1993), which has been linked to decision making in risky situations (Loewenstein et al. 2001, Loewenstein and Lerner 2003). Finally, Fehr-Duda et al. (2011) show that the effect of incidental feelings on decision making under risk is not gender neutral. Despite men and women having statistically equivalent self-reported moods, women in a 'better than normal' mood tend to rate probabilities more optimistically, while men tend to use expected values as a guide in their decision which immunizes them from the effect of mood states.

It is an open question whether or not there is a neural explanation for the differences in men's and women's emotional responses to risk. However, existence of such a link would provide an important pathway through which gender differences in neural functioning could result in gender disparities in economic outcomes, including in wages, occupational position, etc. It might also potentially argue for the insurance products (e.g. disability insurance) and public policies (e.g. unemployment benefits) that protect individuals against bad labor market outcomes to be made gender-specific as a means of levelling the biological playing field.

\subsection{Self-control}

Self-control allows individuals to resist immediate temptation (i.e. choices with immediate payoffs and long-term costs) and make long-term investments (i.e. choices with immediate costs and long-term payoffs). Consequently, many economists view self-control problems as a form of time-inconsistent discounting. That is, individuals discount future benefits more heavily when the choice is immediate than when it is further away. Economists are 
increasingly recognizing the importance of temptation and self-control in inter-temporal decision making. ${ }^{14}$

Neuroscience is shedding light on the neural origins of self-control. McClure et al. (2004), for example, hypothesize that the discrepancy in individuals' short- and long-run preferences is due to the differential activation of different neural systems. Using magnetic resonance imaging, the authors find that, consistent with their hypothesis, parts of the limbic system are activated when decisions involve immediate rewards, while regions of the lateral prefrontal cortex and posterior parietal cortex are engaged irrespective of time delay. Other research directly challenges this separate neural system hypothesis. In particular, Kable and Glimcher (2007, 2010) present evidence that the neural activity of individuals making repeated delayed-option choices does not depend on the length of delay. Thus, while there is "unambiguous evidence that the subjective value of potential rewards is explicitly represented in the human brain” (Kable and Glimcher 2007, 1625), the nature of that representation remains under investigation.

The ability to exercise self-control is not completely gender neutral. Meta-analyses of the large literature examining gender differences in levels of self-control and related concepts such as risk-seeking, attention problems, and overactivity reveal that females have a small advantage in delaying gratification (Silverman 2003). However, research has not yet addressed whether this gender gap in self-control is the result of disparity in the neural functioning of men's and women's brains. If this were the case, then self-control provides another potential mechanism through which neural processes might result in gendered economic behavior.

The question then arises: what would be the appropriate policy response? Workers' self-control issues have fundamental implications for the efficient design of compensation policies (Gilpatric 2008, Kaur, Kremer, and Mullainathan 2010, Jain 2012, Kaur, Kremer, and Mullainathan 2015). Ideally, public programs like the unemployment benefits system would also provide work incentives that address not only moral hazard, but also workers' self-control problems (Babcock et al. 2012). There are of course limits to the extent to which both firm and social policy can be individually-tailored. Nonetheless, if self-control ultimately proves to be a link between human biology and gendered labor market behavior there may be opportunities to address gender inequalities though optimal policy design.

\footnotetext{
${ }^{14}$ See for example, Thaler and Shefrin (1981); Shefrin and Thaler (1988); Levin (1998); Lee and McCrary (2005); and Ruhm (2012).
} 


\section{Sensory Functioning and Perceptions of Time and Space}

All our knowledge begins with sense, proceeds thence to understanding, and ends with reason...

(Kant 1855, 212)

All of our information about the world around us comes from our sensory systems - vision, auditory (hearing), somatic sensation (touch), gustatory (taste), olfaction (smell), and vestibular (balance/movement). We take information in using our senses, organize and interpret that information, and then respond in an appropriate way. Gender differences in the way we perceive and pay attention to external stimuli are of interest because, if there are sexrelated disparities at the earliest stages of information processing, then it is not unreasonable to expect differences in men's and women's subsequent responses (Halpern 2012).

There is a great deal of evidence that sensory functioning differs for men and women. ${ }^{15}$ For example, women are less tolerant of loud noises, more sensitive to higher frequencies, and, in some cases, better able to hear faint sounds (see Velle 1987, McFadden 1998, Halpern 2012), while men are better at locating the source of a sound (McFadden 1998). Men, on the other hand, have better dynamic visual acuity (Velle 1987), but are less sensitive to color (see Baker and Cornelson 2016) and are 16 times as likely as women to be color-blind (Bowmaker 1998). The loss of hearing and vision that occurs in middle age is also gendered, with men losing the ability to detect high tones at an earlier age and women experiencing age-related vision loss earlier (see Halpern 2012). Women have a clear advantage, which appears to be lifelong, in detecting, discriminating between, and remembering odors (see Brand and Millot 2001, Halpern 2012). ${ }^{16}$ Finally, women are thought to have a better sense of touch and a better ability to taste some things, but not others (Velle 1987, Halpern 2012).

Other research documents differences in the way that men and women perceive time and space. Extensive research, for example, highlights the small, but consistent, disparities in men's and women's temporal cognition, i.e. the recognition of and judgments about the passage of time (see Hancock 2011). In general, women appear to pay more attention to time when they know in advance that they must estimate the passage of time and have better recall when they do not (Block, Hancock, and Zakay 2000).

\footnotetext{
${ }^{15}$ See Baker (1987), Velle (1987), Halpern (2012), and Baker and Cornelson (2016) for reviews.

${ }^{16}$ Interestingly, Monnery-Patris et al. (2009) show that among boys and girls with the same verbal ability, however, girls advantage in olfactory tasks disappears suggesting that gender differences in children's sense of smell is the result of the way they labelled and remembered different odors not in their olfactory system itself.
} 
Interestingly, circadian rhythms are also not gender neutral. Females have shorter circadian clocks predisposing them to earlier wake up times and stronger preferences for morning activities than males (Adan and Natale 2002, Tsai and Li 2004, Duffy et al. 2011). Moreover, women are also better able to 'catch up' on their sleep if they become sleep deprived (Pejovic et al. 2013). These gender differences in sleep patterns have been linked to the gender gap in educational performance. Exploiting quasi-experimental variation in school start times, Lusher and Yasenov (2016) find that as much as 16 percent of the gender gap in academic performance is explained by the fact that boys benefit much more than girls from a later school start time.

There is also extensive evidence that spatial ability, i.e. the capacity to understand and remember the spatial relationship between objects, is gendered. Psychologists view spatial ability as a unique form of intelligence that is distinguishable from other forms of intelligence including verbal skills, reasoning skills, etc. Much of the literature on gender differences in cognitive ability has focused on the various dimensions of spatial ability. In general, males tend to outperform females on spatial tasks, particularly those requiring the mental rotation of spatial information (see Hines 2004, Halpern 2012 for reviews). Spatial ability as been linked to testosterone (Baron-Cohen, Lutchmaya, and Knickmeyer 2004), implying that the gender gap in spatial ability may have a biological basis. Hoffman, Gneezy, and List (2011), however, find that gender gaps in spatial abilities, measured in the time taken to solve a puzzle, which are evident in a patrilineal society disappear in a matrilineal society, while Levine et al. (2005) show that socio-economic background affects the gender gap in children's performance on spatial tasks. Thus, nurture also seems to influence the gender gap in spatial ability.

Sensory functioning and time-space perceptions are perhaps most directly linked to gendered labor market outcomes through the influence they have on men's and women's educational and occupational choices. It seems logical that having a heightened sense of smell, hearing, or taste could give one an edge in working as a perfumer, musician, or chef, while color-blindness certainly precludes working in some occupations, e.g. pilot, police officer, electrician, etc. The most direct evidence of the labor market consequences of heterogeneity in the way that individuals perceive their environment has centered on spatial ability. Specifically, spatial ability has been linked achievement in math and science courses (Delgado and Prieto 2004, Ganley and Vasilyeva 2011), to the decision to study math- and science-related subjects (Casey 1996, Shea, Lubinski, and Benbow 2001, Wai, Lubinski, and 
Benbow 2009), and to employment in a wide range of technological and science-related occupations (McGee 1979, Wai, Lubinski, and Benbow 2009).

To date, it has been difficult to assess how much of the occupational segregation and gender disparities in earnings that we observe might be attributable to sensory functioning and/or perceptions of time and space. In a recent paper, however, Baker and Cornelson (2016) relate gender-based segregation to detailed information about the sensory, motor, and spatial requirements of occupations in the United States. They find that occupational requirements strongly predict the occupational choices of men and women in ways that are largely consistent with the existing research on their relative advantages in sensory functioning and spatial perceptions. Eliminating occupational selection on the basis of these skills would lead occupational segregation to be 23 percent lower, but the gender wage gap to be higher.

\section{Conclusion}

Gender disparities in labor market outcomes transcend political and economic institutions, legal frameworks, social norms, culture, and history. Women earn less than men in virtually all countries in which data exist. There is no doubt that social norms, institutional arrangements and the like all matter enormously for the magnitude of and trends in gender inequalities. However, the existence of a gender pay gap that is both nearly universal and stubbornly persistent is not easily explained by these influences. Moving on to consider the potential biological basis for gender pay inequality is a logical step to take. After all, human biology provides perhaps the only obvious common denominator with the capacity to explain the pervasiveness of the gap. Moreover, advances in reproductive technology and a fall in the relative return to physical strength reduced men's biological advantage in the labor market at a point in time when women began to make rapid progress in closing the gap. Perhaps biology has the capacity to explain trends as well.

Despite the logic of the endeavor we remain a long way from identifying a biological foundation for gender differences in labor market behavior and outcomes. One issue is that the science has not yet reached a stage where we have sufficient certainty about the way that biological functioning influences decision making, let alone what the implications of that might be for gendered labor market behavior. In general, the existing research evidence is largely correlational and does not often lend itself a causal interpretation. Key research findings are frequently not robust to differences in sampling, measurement, model specification, and context. For ethical reasons, many researchers rely on participants 
volunteering for their study, raising questions about external validity and selection bias. All too often, studies are under-powered due to insufficient sample sizes which results in a lack of estimation precision. Publication bias seems to result in positive results being overreported, making it difficult to form judgments about the body of research findings as a whole. Finally, some research fields such as genoeconomics, behavioral endocrinology, affective neuroscience, etc. are still very much in their infancy. There is simply a great deal that science has yet to discover about the biological origins of human behavior.

It is also the case that there is very little clarity about the economic significance of the effect sizes being reported. There are substantial inter-disciplinary differences in the effect size statistics that researchers are prone to report, making it difficult to make comparisons across studies. ${ }^{17}$ Some statistics are not very intuitive and effect sizes themselves are always dependent on the other controls in the model. Even more importantly, it is not straightforward to determine when an effect size is large enough to be economically meaningful. Effects which are small in magnitude may nonetheless be extremely important. For example, small differences in risk or time preferences may translate into large differences in net present values - and hence investment decisions - when discounting occurs over long time horizons. Making judgments about the importance of biological effect sizes is especially challenging because we do not have a commonly understood metric for judging what 'large enough to be important' might mean. ${ }^{18}$ More research is needed to determine whether any biological effects on gender disparities in behavior are in fact economically meaningful and capable of explaining the gender inequality in labor market outcomes that we observe.

Finally, we do not have a smoking gun. That is to say, we do not have an obvious mechanism through which the biological differences in men's and women's behavior that have been identified so far could reasonably translate into a wage penalty for women on average. It is not only that we lack causal evidence, though this is an obvious problem (see Coates and Herbert 2008, Zethraeus et al. 2009 for example). The bigger issue is that the biological differences between men and women do not give either an obvious overall labor market advantage. Gender differences do not necessarily imply gender deficits. Women appear to have a small advantage over men in delaying gratification and in sensory functioning, for example, and while women's heightened risk aversion is likely to be a liability in some jobs, it is an asset in others. Thus, the evidence to date is more logically

\footnotetext{
${ }^{17}$ See Halpern (2012) for a discussion.

${ }^{18}$ See Manski (2011) for a discussion of this issue in the context of the policy implications of behavioral genetics and Halpern (2012) for a similar discussion in the context of medical research.
} 
consistent with a biological basis to the type of work that men and women do than it is with the existence of a nearly universal and stubbornly persistent gender pay gap. 


\section{References}

Adan, Ana, and Vincenzo Natale. 2002. "Gender differences in morningness-eveningness preference." Chronobiology International 19 (4):709-720.

Akerlof, George A., and Rachel E. Kranton. 2000. "Economics and identity." The Quarterly Journal of Economics 115 (3):715-753.

Apicella, Coren L., Justin M. Carré, and Anna Dreber. 2015. "Testosterone and economic risk taking: A review." Adaptive Human Behavior and Physiology 1 (3):358-385.

Apicella, Coren L., Anna Dreber, Benjamin Campbell, Peter B. Gray, Moshe Hoffman, and Anthony C. Little. 2008. "Testosterone and financial risk preferences." Evolution and Human Behavior 29 (6):384-390.

Archer, John. 2006. "Testosterone and human aggression: An evaluation of the challenge hypothesis." Neuroscience \& Biobehavioral Reviews 30 (3):319-345.

Azmat, Ghazala, and Barbara Petrongolo. 2014. "Gender and the labor market: What have we learned from field and lab experiments?" Labour Economics 30:32-40.

Babcock, Linda, William J Congdon, Lawrence F Katz, and Sendhil Mullainathan. 2012. "Notes on behavioral economics and labor market policy." IZA Journal of Labor Policy 1:2.

Baker, Mary Anne. 1987. "Sensory functioning." In Sex Differences in Human Performance, edited by Mary Anne Baker, 5-36. Chichester, Toronto: John Wiley \& Sons.

Baker, Michael, and Kirsten Cornelson. 2016. "Gender based occupational segregation and sex differences in sensory, motor and spatial aptitudes." NBER Working Paper No. 22248.

Baron-Cohen, Simon. 2002. "The extreme male brain theory of autism." Trends in Cognitive Sciences 6 (6):248-254.

Baron-Cohen, Simon. 2003. The Essential Difference: Men, Women and the Extreme Male Brain. London: Basic Books.

Baron-Cohen, Simon, Svetlana Lutchmaya, and Rebecca Knickmeyer. 2004. Prenatal Testosterone in Mind: Amniotic Fluid Studies. United States of America: MIT Press.

Baron-Cohen, Simon, Jennifer Richler, Dheraj Bisarya, Nhishanth Gurunathan, and Sally Wheelwright. 2003. "The systemizing quotient: An investigation of adults with Asperger syndrome or high-functioning autism, and normal sex differences." Philosophical Transactions of the Royal Society of London B: Biological Sciences 358 (1430):361-374.

Bateup, Helen S., Alan Booth, Elizabeth A. Shirtcliff, and Douglas A. Granger. 2002. "Testosterone, cortisol, and women's competition." Evolution and Human Behavior 23 (3):181-192.

Beauchamp, Jonathan P., David Cesarini, Magnus Johannesson, Matthijs J. H. M. van der Loos, Philipp D. Koellinger, Patrick J. F. Groenen, James H. Fowler, J. Niels Rosenquist, A. Roy Thurik, and Nicholas A. Christakis. 2011. "Molecular genetics and economics." The Journal of Economic Perspectives 25 (4):57-82.

Becker, Gary S. 1976. "Altruism, egoism, and genetic fitness: Economics and sociobiology." Journal of Economic Literature 14 (3):817-826.

Benjamin, Daniel J., David Cesarini, Christopher F. Chabris, Edward L. Glaeser, David I. Laibson, Vilmundur Guðnason, Tamara B. Harris, et al. 2012. "The promises and pitfalls of genoeconomics." Annual Review of Economics 4:627-662.

Benjamin, Daniel J., Christopher F. Chabris, Edward L. Glaeser, Vilmunder Gudnason, Tamara B. Harris, David I. Laibson, Lenore Launer, and Shaun Purcell. 2008. "Genoeconomics." In Biosocial Surveys, edited by Maxine Weinstein, James W. 
Vaupel and Kenneth W. Wachter, 304-335. Washington, DC: National Academies Press.

Bertrand, Marianne. 2011. "New perspectives on gender." In Handbook of Labor Economics, edited by David Card and Orley Ashenfelter, 1543-1590. Amsterdam: North Holland.

Bertrand, Marianne, Emir Kamenica, and Jessica Pan. 2015. "Gender identity and relative income within households." The Quarterly Journal of Economics 130 (2):571-614.

Björklund, Anders, Markus Jäntti, and Gary Solon. 2005. "Influences of nature and nurture on earnings variation: A report on a study of various sibling types in Sweden." In Unequal Chances, edited by Samuel Bowles, Herbert Gintis and Melissa O. Groves, 145-164. New Jersey: Princeton University Press.

Blau, Francine D., Peter Brummund, and Albert Yung-Hsu Liu. 2013. "Trends in occupational segregation by gender 1970-2009: Adjusting for the impact of changes in the occupational coding system." Demography 50 (2):471-492.

Blau, Francine D., and Lawrence M. Kahn. "The gender wage gap: Extent, trends, and explanations." Journal of Economic Literature, forthcoming.

Blau, Francine D., and Lawrence M. Kahn. 2006. "The US gender pay gap in the 1990s: Slowing convergence." Industrial \& Labor Relations Review 60 (1):45-66.

Block, Richard A., Peter A. Hancock, and Dan Zakay. 2000. "Sex differences in duration judgments: A meta-analytic review." Memory \& Cognition 28 (8):1333-1346.

Booth, Alison L. 2009. "Gender and competition." Labour Economics 16 (6):599-606.

Bos, Peter A., Jaak Panksepp, Rose-Marie Bluthé, and Jack van Honk. 2012. "Acute effects of steroid hormones and neuropeptides on human social-emotional behavior: A review of single administration studies." Frontiers in Neuroendocrinology 33 (1):1735.

Bowmaker, J.K. 1998. "Visual pigments and molecular genetics of color blindness." Physiology 13 (2):63-69.

Brañas-Garza, Pablo, and Aldo Rustichini. 2011. "Organizing effects of testosterone and economic behavior: Not just risk taking." PloS ONE 6 (12):e29842. doi:10.1371/journal.pone.0029842.

Brand, Gérard, and Jean-Louis Millot. 2001. "Sex differences in human olfaction: Between evidence and enigma." The Quarterly Journal of Experimental Psychology: Section B 54 (3):259-270.

Branigan, Amelia R., Kenneth J. McCallum, and Jeremy Freese. 2013. "Variation in the heritability of educational attainment: An international meta-analysis." Social Forces 92 (1):109-140.

Bröder, Arndt, and Natalia Hohmann. 2003. "Variations in risk taking behavior over the menstrual cycle: An improved replication." Evolution and Human Behavior 24 (6):391-398.

Brody, Leslie R. 1993. "On understanding gender differences in the expression of emotion." In Human Feelings: Explorations in Affect Development and Meaning, edited by Steven L. Ablon, Daniel P. Brown, Edward J. Khantzian and John E. Mack, 87-121. Hillsdale, NJ: The Analytic Press.

Bruhin, Adrian, Helga Fehr-Duda, and Thomas Epper. 2010. "Risk and rationality: Uncovering heterogeneity in probability distortion." Econometrica 78 (4):1375-1412.

Carpenter, Jeffrey P., Justin R. Garcia, and J. Koji Lum. 2011. "Dopamine receptor genes predict risk preferences, time preferences, and related economic choices." Journal of Risk and Uncertainty 42 (3):233-261.

Carré, Justin M., and Cheryl M. McCormick. 2008. "Aggressive behavior and change in salivary testosterone concentrations predict willingness to engage in a competitive task." Hormones and Behavior 54 (3):403-409. 
Casey, M. Beth. 1996. "Understanding individual differences in spatial ability within females: A nature/nurture interactionist framework." Developmental Review 16 (3):241-260.

Cesarini, David, Christopher T. Dawes, Magnus Johannesson, Paul Lichtenstein, and Björn Wallace. 2009. "Genetic variation in preferences for giving and risk taking." The Quarterly Journal of Economics 124 (2):809-842.

Chabris, Christopher F., James J. Lee, David Cesarini, Daniel J. Benjamin, and David I. Laibson. 2015. "The fourth law of behavior genetics." Current Directions in Psychological Science 24 (4):304-312.

Chen, Yan, Peter Katuščák, and Emre Ozdenoren. 2013. "Why can’t a woman bid more like a man?" Games and Economic Behavior 77 (1):181-213.

Coates, John M., Mark Gurnell, and Aldo Rustichini. 2009. "Second-to-fourth digit ratio predicts success among high-frequency financial traders." Proceedings of the National Academy of Sciences 106 (2):623-628.

Coates, John M., and Joe Herbert. 2008. "Endogenous steroids and financial risk taking on a London trading floor." Proceedings of the National Academy of Sciences 105 (16):6167-6172.

Cronqvist, Henrik, Alessandro Previtero, Stephan Siegel, and Roderick E. White. 2015. "The fetal origins hypothesis in finance: Prenatal environment, the gender gap, and investor behavior." Review of Financial Studies 29 (3):739-786.

Croson, Rachel, and Uri Gneezy. 2009. "Gender differences in preferences." Journal of Economic Literature 47 (2):448-474.

Delgado, Ana R., and Gerardo Prieto. 2004. "Cognitive mediators and sex-related differences in mathematics." Intelligence 32 (1):25-32.

Dreber, Anna, Coren L. Apicella, Dan T.A. Eisenberg, Justin R. Garcia, Richard S. Zamore, J. Koji Lum, and Benjamin Campbell. 2009. "The 7R polymorphism in the dopamine receptor D 4 gene (DRD4) is associated with financial risk taking in men." Evolution and Human Behavior 30 (2):85-92.

Dreber, Anna, and Moshe Hoffman. 2007. "Portfolio selection in utero." mimeo, Stockholm School of Economics.

Dreber, Anna, and Moshe Hoffman. 2010. "Biological basis of sex differences in risk aversion and competitiveness." mimeo.

Drichoutis, Andreas C., and Rodolfo M. Nayga. 2015. "Do risk and time preferences have biological roots?" Southern Economic Journal 82 (1):235-256.

Drydakis, Nick. "Brain types and wages." The Manchester School. Published electronically November 10, 2015. doi:10.1111/manc.12142.

Duffy, Jeanne F., Sean W. Cain, Anne-Marie Chang, Andrew J.K. Phillips, Mirjam Y. Münch, Claude Gronfier, James K. Wyatt, Derk-Jan Dijk, Kenneth P. Wright, and Charles A. Czeisler. 2011. "Sex difference in the near-24-hour intrinsic period of the human circadian timing system." Proceedings of the National Academy of Sciences 108 (Supplement 3):15602-15608.

Ebstein, Richard P., Salomon Israel, Soo Hong Chew, Songfa Zhong, and Ariel Knafo. 2010. "Genetics of human social behavior." Neuron 65 (6):831-844.

Eckel, Catherine C., and Philip J. Grossman. 2008a. "Differences in the economic decisions of men and women: Experimental evidence." In Handbook of Experimental Economics Results, edited by Charles R. Plott and Vernon L. Smith, 509-519. Amsterdam: North Holland.

Eckel, Catherine C., and Philip J. Grossman. 2008b. "Men, women and risk aversion: Experimental evidence." In Handbook of Experimental Economics Results, edited by Charles R. Plott and Vernon L. Smith, 1061-1073. Amsterdam: North Holland. 
Fehr-Duda, Helga, Manuele De Gennaro, and Renate Schubert. 2006. "Gender, financial risk, and probability weights." Theory and Decision 60:283-313.

Fehr-Duda, Helga, Thomas Epper, Adrian Bruhin, and Renate Schubert. 2011. "Risk and rationality: The effects of mood and decision rules on probability weighting." Journal of Economic Behavior \& Organization 78:14-24.

Flynn, James, Paul Slovic, and Chris K. Mertz. 1994. "Gender, race, and perception of environmental health risks." Risk Analysis 14 (6):1101-1108.

Fujita, Frank, Ed Diener, and Ed Sandvik. 1991. "Gender differences in negative affect and well-being: The case for emotional intensity." Journal of Personality and Social Psychology 61 (3):427-434.

Galton, Francis. 1883. Inquiries into Human Faculty and its Development. New York, NY: Macmillan Co.

Ganley, Colleen M., and Marina Vasilyeva. 2011. "Sex differences in the relation between math performance, spatial skills, and attitudes." Journal of Applied Developmental Psychology 32 (4):235-242.

Garbarino, Ellen, Robert Slonim, and Justin Sydnor. 2011. "Digit ratios (2D: 4D) as predictors of risky decision making for both sexes." Journal of Risk and Uncertainty 42 (1):1-26.

Gielen, Anne C., Jessica Holmes, and Caitlin Myers. 2016. "Prenatal testosterone and the earnings of men and women." Journal of Human Resources 51 (1):30-61.

Gilpatric, Scott M. 2008. "Present-biased preferences, self-awareness and shirking." Journal of Economic Behavior \& Organization 67 (3-4):735-754.

Goldberger, Arthur S. 1979. "Heritability." Economica 46 (184):327-347.

Guiso, Luigi, and Aldo Rustichini. 2011. "Understanding the size and profitability of firms: The role of a biological factor." CEPR Discussion Paper No. DP8205.

Halpern, Diane F. 2012. Sex Differences in Cognitive Abilities. 4th ed. New York: Psychology Press.

Hampson, Elizabeth, Connie L. Ellis, and Christine M. Tenk. 2008. "On the relation between 2D: 4D and sex-dimorphic personality traits." Archives of Sexual Behavior 37 (1):133-144.

Hancock, Peter A. 2011. Cognitive Differences in the Ways Men and Women Perceive the Dimension and Duration of Time: Contrasting Gaia and Chronos. Lewiston, NY: Edwin Mellen Press.

Herrmann, Mariesa A., and Jonah E. Rockoff. 2012. "Does menstruation explain gender gaps in work absenteeism?" Journal of Human Resources 47 (2):493-508.

Herrmann, Mariesa A., and Jonah E. Rockoff. 2013. "Do menstrual problems explain gender gaps in absenteeism and earnings?: Evidence from the National Health Interview Survey." Labour Economics 24:12-22.

Hines, Melissa. 2004. Brain Gender. New York: Oxford University Press.

Hirshleifer, Jack. 1977. "Economics from a biological viewpoint." The Journal of Law \& Economics 20 (1):1-52.

Hoffman, Moshe, Uri Gneezy, and John A. List. 2011. "Nurture affects gender differences in spatial abilities." Proceedings of the National Academy of Sciences 108 (36):1478614788.

Ichino, Andrea, and Enrico Moretti. 2009. "Biological gender differences, absenteeism, and the earnings gap." American Economic Journal: Applied Economics 1 (1):183-218.

Ilies, Remus, Richard D. Arvey, and Thomas J. Bouchard. 2006. "Darwinism, behavioral genetics, and organizational behavior: A review and agenda for future research." Journal of Organizational Behavior 27 (2):121-141. 
Jain, Sanjay. 2012. "Self-control and incentives: An analysis of multiperiod quota plans." Marketing Science 31 (5):855-869.

Kable, Joseph W., and Paul W. Glimcher. 2007. "The neural correlates of subjective value during intertemporal choice." Nature Neuroscience 10 (12):1625-1633.

Kable, Joseph W., and Paul W. Glimcher. 2010. "An "as soon as possible" effect in human intertemporal decision making: Behavioral evidence and neural mechanisms." Journal of Neurophysiology 103 (5):2513-2531.

Kant, Immanuel. 1855. Critique of Pure Reason, translated from the German of Immanuel Kant; by J.M.D. Meiklejohn. London: Bohn.

Kaur, Supreet, Michael Kremer, and Sendhil Mullainathan. 2010. "Self-control and the development of work arrangements." The American Economic Review 100 (2):624628.

Kaur, Supreet, Michael Kremer, and Sendhil Mullainathan. 2015. "Self-control at work." Journal of Political Economy 123 (6):1227-1277.

Lazzaro, Stephanie C., Robb B. Rutledge, Daniel R. Burghart, and Paul W. Glimcher. 2016. "The impact of menstrual cycle phase on economic choice and rationality." PloS ONE 11 (1):e0144080. doi:10.1371/journal.pone.0144080.

Le, Anh T., Paul W. Miller, Wendy S. Slutske, and Nicholas G. Martin. 2011. "Attitudes towards economic risk and the gender pay gap." Labour Economics 18 (4):555-561.

LeDoux, Joseph E. 1995. "Emotion: Clues from the brain." Annual Review of Psychology 46:209-235.

Lee, David S., and Justin McCrary. 2005. "Crime, punishment, and myopia." NBER Working Paper No. 11491.

Levin, Laurence. 1998. "Are assets fungible?: Testing the behavioral theory of life-cycle savings." Journal of Economic Behavior \& Organization 36 (1):59-83.

Levine, Susan C., Marina Vasilyeva, Stella F. Lourenco, Nora S. Newcombe, and Janellen Huttenlocher. 2005. "Socioeconomic status modifies the sex difference in spatial skill." Psychological Science 16 (11):841-845.

Lippa, Richard A. 2006. "Finger lengths, 2D: 4D ratios, and their relation to gender-related personality traits and the Big Five." Biological Psychology 71 (1):116-121.

Loewenstein, George. 2000. "Emotions in economic theory and economic behavior." The American Economic Review 90 (2):426-432.

Loewenstein, George F., Elke U. Weber, Christopher K. Hsee, and Ned Welch. 2001. "Risk as feelings." Psychological Bulletin 127 (2):267-286.

Loewenstein, George, and Jennifer S. Lerner. 2003. "The role of affect in decision making." In Handbook of Affective Science, edited by Klaus Scherer, Richard Davidson and H. Hill Goldsmith. Oxford: Oxford University Press.

Lundborg, Petter, and Henrik Andersson. 2008. "Gender, risk perceptions, and smoking behavior." Journal of Health Economics 27 (5):1299-1311.

Lusher, Lester, and Vasil Yasenov. 2016. "Gender performance gaps: Quasi-experimental evidence on the role of gender differences in sleep cycles." IZA Discussion Paper No. 10012.

Manning, J.T., D. Scutt, J. Wilson, and D.I. Lewis-Jones. 1998. "The ratio of 2nd to 4th digit length: a predictor of sperm numbers and concentrations of testosterone, luteinizing hormone and oestrogen." Human Reproduction 13 (11):3000-3004.

Manning, John T., Stian Reimers, Simon Baron-Cohen, Sally Wheelwright, and Bernhard Fink. 2010. "Sexually dimorphic traits (digit ratio, body height, systemizingempathizing scores) and gender segregation between occupations: Evidence from the BBC internet study." Personality and Individual Differences 49 (5):511-515. 
Manski, Charles F. 2011. "Genes, eyeglasses, and social policy." The Journal of Economic Perspectives 25 (4):83-93.

Marshall, Alfred. 1920. Principles of Economics: An Introductory Volume. 8th ed. London: Macmillan and Co., (1925 reprinting).

McClure, Samuel M., David I. Laibson, George Loewenstein, and Jonathan D. Cohen. 2004. "Separate neural systems value immediate and delayed monetary rewards." Science 306 (5695):503-507.

McFadden, Dennis. 1998. "Sex differences in the auditory system." Developmental Neuropsychology 14 (2-3):261-298.

McGee, Mark G. 1979. "Human spatial abilities: Psychometric studies and environmental, genetic, hormonal, and neurological influences." Psychological Bulletin 86 (5):889918.

Monnery-Patris, S., C. Rouby, S. Nicklaus, and S. Issanchou. 2009. "Development of olfactory ability in children: Sensitivity and identification." Developmental Psychobiology 51 (3):268-276.

Nelson, Randy J. 2011. An Introduction to Behavioral Endocrinology. 4th ed. Sunderland, MA: Sinauer Associates.

Niederle, Muriel, and Lise Vesterlund. 2011. "Gender and competition." The Annual Review of Economics 3 (1):601-630.

Nye, J. V. C., and E. Orel. 2015. "The influence of prenatal hormones on occupational choice: 2D:4D evidence from Moscow." Personality and Individual Differences 78:39-42.

O’Reilly, Jacqueline, Mark Smith, Simon Deakin, and Brendan Burchell. 2015. "Equal pay as a moving target: International perspectives on forty-years of addressing the gender pay gap." Cambridge Journal of Economics 39 (2):299-317.

Panksepp, J. 1998. Affective Neuroscience. New York, N.Y.: Oxford University Press.

Papageorge, Nicholas W., and Kevin Thom. 2016. "Genes, education, and labor market outcomes: Evidence from the health and retirement study." IZA Discussion Paper No. 10200.

Patton, Eric, and Gary Johns. 2007. "Women's absenteeism in the popular press: Evidence for a gender-specific absence culture." Human Relations 60 (11):1579-1612.

Pearson, Matthew, and Burkhard C. Schipper. 2013. "Menstrual cycle and competitive bidding." Games and Economic Behavior 78:1-20.

Pejovic, Slobodanka, Maria Basta, Alexandros N. Vgontzas, Ilia Kritikou, Michele L. Shaffer, Marina Tsaoussoglou, David Stiffler, Zacharias Stefanakis, Edward O. Bixler, and George P. Chrousos. 2013. "Effects of recovery sleep after one work week of mild sleep restriction on interleukin-6 and cortisol secretion and daytime sleepiness and performance." American Journal of Physiology-Endocrinology and Metabolism 305 (7):E890-E896. doi:10.1152/ajpendo.00301.2013.

Robson, Arthur J. 1996. "A biological basis for expected and non-expected utility." Journal of Economic Theory 68 (2):397-424.

Robson, Arthur J. 2001. "The biological basis of economic behavior." Journal of Economic Literature 39 (1):11-33.

Rogers, Alan R. 1994. "Evolution of time preference by natural selection." The American Economic Review 84 (3):460-481.

Ruhm, Christopher J. 2012. "Understanding overeating and obesity." Journal of Health Economics 31 (6):781-796.

Sapienza, Paola, Luigi Zingales, and Dario Maestripieri. 2009. "Gender differences in financial risk aversion and career choices are affected by testosterone." Proceedings of the National Academy of Sciences 106 (36):15268-15273. 
Schipper, Burkhard. 2012. "Sex hormones and choice under risk." University of California, working paper No. 12,7.

Shea, Daniel L., David Lubinski, and Camilla P. Benbow. 2001. "Importance of assessing spatial ability in intellectually talented young adolescents: A 20-year longitudinal study." Journal of Educational Psychology 93 (3):604-614.

Shefrin, Hersh M., and Richard H. Thaler. 1988. "The behavioral life-cycle hypothesis." Economic Inquiry 26 (4):609-643.

Silverman, Irwin W. 2003. "Gender differences in delay of gratification: A meta-analysis." Sex Roles 49 (9-10):451-463.

Silverman, Jane M., and Donald S. Kumka. 1987. "Gender differences in attitudes toward nuclear war and disarmament." Sex Roles 16 (3-4):189-203.

Spigner, Clarence, Wesley E. Hawkins, and Wendy Loren. 1993. "Gender differences in perception of risk associated with alcohol and drug use among college students." Women \& Health 20 (1):87-97.

Takahashi, Taiki, Kikue Sakaguchi, Mariko Oki, and Toshikazu Hasegawa. 2008. "Sex hormonal modulation of hyperbolic discount factor in men." Journal of Neuroscience, Psychology, and Economics 1 (1):7-16.

Taubman, Paul. 1976. "The determinants of earnings: Genetics, family, and other environments: A study of white male twins." The American Economic Review 66 (5):858-870.

Thaler, Richard H., and Hersh M. Shefrin. 1981. "An economic theory of self-control." The Journal of Political Economy:392-406.

Tsai, Ling-Ling, and Sheng-Ping Li. 2004. "Sleep patterns in college students: Gender and grade differences." Journal of Psychosomatic Research 56 (2):231-237.

Tymula, Agnieszka, and Paul W. Glimcher. "How are emotions intergrated into choice?" In The Nature of Emotion edited by R. J. Davidson, A. J. Shackman, A. S. Fox and R. C Lapate. New York: Oxford University Press, forthcoming.

Van der Loos, Matthijs J.H.M, Robin Haring, Cornelius A. Rietveld, Sebastian E. Baumeister, Patrick J.F. Groenen, Albert Hofman, Frank H. de Jong, et al. 2013. "Serum testosterone levels in males are not associated with entrepreneurial behavior in two independent observational studies." Physiology \& Behavior 119:110-114.

Van der Loos, Matthijs J.H.M., Cornelius A. Rietveld, Niina Eklund, Philipp D. Koellinger, Fernando Rivadeneira, Gonçalo R. Abecasis, Georgina A. Ankra-Badu, et al. 2013. "The molecular genetic architecture of self-employment." PloS ONE 8 (4):e60542. doi:10.1371/journal.pone.0060542.

VandenHeuvel, Audrey, and Mark Wooden. 1995. "Do explanations of absenteeism differ for men and women?" Human Relations 48 (11):1309-1329.

Velle, Weiert. 1987. "Sex differences in sensory functions." Perspectives in Biology and Medicine 30 (4):490-522.

Wai, Jonathan, David Lubinski, and Camilla P. Benbow. 2009. "Spatial ability for STEM domains: Aligning over 50 years of cumulative psychological knowledge solidifies its importance." Journal of Educational Psychology 101 (4):817.

Weichselbaumer, Doris, and Rudolf Winter-Ebmer. 2005. "A meta-analysis of the international gender wage gap." Journal of Economic Surveys 19 (3):479-511.

Weis, Sophie E., Annika Firker, and Juergen Hennig. 2007. "Associations between the second to fourth digit ratio and career interests." Personality and Individual Differences 43 (3):485-493.

Wozniak, David, William T. Harbaugh, and Ulrich Mayr. 2014. "The menstrual cycle and performance feedback alter gender differences in competitive choices." Journal of Labor Economics 32 (1):161-198. 
Zethraeus, Niklas, Ljiljana Kocoska-Maras, Tore Ellingsen, B.O. Von Schoultz, Angelica L. Hirschberg, and Magnus Johannesson. 2009. "A randomized trial of the effect of estrogen and testosterone on economic behavior." Proceedings of the National Academy of Sciences 106 (16):6535-6538.

Zhang, Zhen, Michael J. Zyphur, Jayanth Narayanan, Richard D. Arvey, Sankalp Chaturvedi, Bruce J. Avolio, Paul Lichtenstein, and Gerry Larsson. 2009. "The genetic basis of entrepreneurship: Effects of gender and personality." Organizational Behavior and Human Decision Processes 110 (2):93-107.

Zhong, Songfa, Salomon Israel, Idan Shalev, Xue Hong, Richard P. Ebstein, and Chew Soo Hong. 2010. "Dopamine D4 receptor gene associated with fairness preference in ultimatum game." PLoS ONE 5 (11):e13765. doi:10.1371/journal.pone.0013765.

Zhong, Songfa, Israel Salomon, Hong Xue, Richard P. Ebstein, and Soo Hong Chew. 2009. "Monoamine oxidase a gene (MAOA) associated with attitude towards longshot risks." PLoS ONE 4 (12):e8516. doi:10.1371/journal.pone.0008516. 